\title{
Gastroparesis and Symptoms-Sketchy Relationships
}

ISSN: 2637-7632

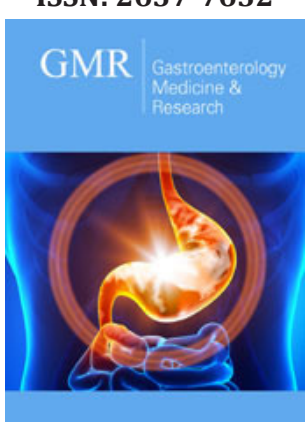

*Corresponding author: Frieling T, Director of the Medical Clinic II, Clinic for Internal Medicine with gastroenterology, hepatology, infectious diseases, neurogastroenterology, gastrointestinal oncology, hematooncology and palliative medicine 47805 Krefeld, Lutherplatz 40, Germany

Submission: 海 August 16, 2021

Published: 温 August 30, 2021

Volume 6 - Issue 2

How to cite this article: Frieling $\mathrm{T}$. Gastroparesis and Symptoms-Sketchy Relationships. Gastro Med Res. 6(2). GMR. 000631.2021

DOI: 10.31031/GMR.2021.06.000631

Copyright@ Frieling T, This article is distributed under the terms of the Creative Commons Attribution 4.0 International License, which permits unrestricted use and redistribution provided that the original author and source are credited.

\section{Frieling T*}

Director of the Medical Clinic II, Germany

\begin{abstract}
The relation between gastric emptying and symptoms is still unclear. The conception that improvement of gastric outflow or motoric function by Gastric Peroral Endoscopic Pyloromyotomy (G-POEM) or Gastric Electrical Stimulation (GES) would improve gastrointestinal symptoms simplifies the complexity of gastric dysfunction. It is still unclear why some patients with gastroparesis and dyspeptic symptoms benefit from GES. Besides placebo effects alteration of visceral perception has been suggested.
\end{abstract}

\section{Introduction}

\section{Gastric dysfunction is caused by complex gastrointestinal pathophysiology}

Normal gastric emptying is controlled by complex gastrointestinal physiologic functions. These comprise regular fundic tone with sufficient receptive and adaptive relaxation, tonic and peristaltic contractions, regular antroduodenal coordination, effective antral motor pump with grinding, gastric eurhythmia, normal sensory function and duodenal feedback. The predominant and clinical measurable gastric dysfunction is Gastroparesis (GP) with delay of gastric emptying. GP can be secondary through cerebral damage, vagal nerve disturbance, medical side effect, paraneoplasia, endocrinological diseases and infection. However, nearly half of the cases are classified as idiopathic. The diagnosis of clinically relevant idiopathic GP is based on the combination of characteristic symptoms in conjunction with objective evidence of delayed gastric emptying in the absence of mechanical obstruction [1-3].

\section{Poor relationship between gastric dysfunction and clinical symptoms}

Measurement of delayed gastric emptying time as part of multiple gastric dysfunctions time by scintigraphy and breath tests is established in clinical practice. Most clinicians believe that GP is the main cause for clinical symptoms such as nausea, vomiting, epigastric pain, early satiety, and weight loss. However, the relationship between gastric dysfunction and symptoms are not as clear-cut as considered by many physicians. This problem is evident by the finding that only disturbed gastric fundic relaxation significantly correlates with early satiety [4], whereas all the other gastric dysfunctions do not significantly match with symptoms. Especially, the relation between gastric emptying and symptoms is still unclear [5-14]. In addition, interpretation of gastrointestinal symptoms in GP in relation to its pathophysiology is challenging because they show a great overlap with other disorders such as functional dyspepsia or irritable bowel syndrome [2]. Furthermore, gastric emptying as measured by scintigraphy or breath tests show a wide range of normality making differentiation between clinically relevant normal and abnormal gastric emptying difficult in some cases. 


\section{Pitfalls in the treatment of GP and symptoms}

Because of the poor relationship between gastric emptying and symptoms and the heterogeneous patient group rational pathophysiological-based treatment in idiopathic GP is difficult. The conception that improvement of gastric outflow or motoric function by gastric peroral endoscopic pyloromyotomy (G-POEM) or Gastric Electrical Stimulation (GES) would improve gastrointestinal symptoms simplifies the complexity of gastric dysfunction. This dilemma $[15,16]$ is obvious in two recent studies of Gastric Peroral Endoscopic Pyloromyotomy (G-POEM) and Gastric Electrical Stimulation (GES) in patients with idiopathic GP [17] and a randomized double-blind study in patients with refractory emesis with and without GP [18]. In addition, numerous metaanalyes point to the low quality of studies with GES [19] and failed to find robust effects of GES on gastric emptying [20-22]. Major criticism of the metaanalyses were potential bias because many studies were conducted by one group and sponsored by Medtronic (Minneapolis, USA), variation in the methods used to assess the improvement in symptoms in the patients with GES implants [20], substantial discrepancies between the reported results of controlled and open label GES studies, raising questions about the use of GES outside of defined clinical trials [21]. The lack of randomized controlled trials demonstrating benefit suggests the possibility of an underlying placebo effect [22]. However, it is still unclear why some patients with GP and dyspeptic symptoms benefit from GES. Besides placebo effects which may reach up to $50 \%$ in functional dyspepsia alteration of visceral perception as it has been suggested with endoscopic reflux therapy [23-25] may be an explanation. Further studies to elucidate this problem are necessary [26].

\section{Conclusion}

Regulation of gastric functions is complex. Gastric emptying and dyspeptic symptoms show poor correlation. Treatment by Gastric Electrical Stimulation (GES) or Gastric Peroral Endoscopic Pyloromyotomy (G-POEM) are beneficial only in subgroups of patients with gastroparesis. GES has only minor effect of gastric emptying. Besides placebo effects, alteration of visceral perception may be a potential mechanism.

\section{References}

1. Stein B, Everhart KK, Brian E Lacy BE (2015) Gastroparesis: A review of current diagnosis and treatment options. J Clin Gastroenterol 49(7): 550-558.

2. Camilleri M, Chedid V, Ford AC, Haruma K, Horowitz M, et al. (2018) Gastroparesis. Nat Rev Dis Primers 4(1): 41.

3. Camilleri M, Dilmaghani S, Vosoughi K, Zheng T (2021) A North American perspective on the ESNM consensus statement on gastroparesis. Neurogastroenterol Motil 33(8): e14174.

4. Tack J, Talley NJ, Camilleri M, Holtmann G, Hu P, et al. (2006) Functional gastroduodenal disorders. Gastroenterology 130(5): 1466-1479.

5. Jones KL, Russo A, Stevens JE, Wishart JM, Berry MK, et al. (2001) Predictors of delayed gastric emptying in diabetes. Diabetes Care 24(7): 1264-1269.

6. Janssen P, Harris MS, Jones J, Masaoka T, Farré R, et al. (2013) The relation between symptom improvement and gastric emptying in the treatment of diabetic and idiopathic gastroparesis. Am J Gastroenterol 108(9): 1382-1391

7. Lembo A, Camilleri M, McCallum R, Sastre R, Breton C, et al. (2016) Relamorelin reduces vomiting frequency and severity and accelerates gastric emptying in adults with diabetic gastroparesis. Gastroenterology 151(1): 87-96.

8. Hasler WL (2011) Gastroparesis: Pathogenesis, diagnosis and management. Nat Rev Gastroenterol Hepatol 8(8): 438-453.

9. Horowitz M, Maddox AF, Wishart JM, Harding PE, Chatterton BE, et al. (1991) Relationships between oesophageal transit and solid and liquid gastric emptying in diabetes mellitus. Eur J Nucl Med 18(4): 229-234.

10. Pasricha PJ, Colvin R, Yates K, Hasler WL, Abell TL, et al. (2011) Characteristics of patients with chronic unexplained nausea and vomiting and normal gastric emptying. Clin Gastroenterol Hepatol 9(7): 567-576.

11. Bharucha AE, Camilleri M, Forstrom LA, Zinsmeister AR (2009) Relationship between clinical features and gastric emptying disturbances in diabetes mellitus. Clin Endocrinol 70(3): 415-420.

12. Hasler WL, May KP, Wilson LA, Natta MV, Parkman HP, et al. (2018) Relating gastric scintigraphy and symptoms to motility capsule transit and pressure findings in suspected gastroparesis. Neurogastroenterol Motil 30(2).

13. Galil MA, Critchley M, Mackie CR (1993) Isotope gastric emptying tests in clinical practice: Expectation, outcome, and utility. Gut 34(7): 916-919.

14. Vijayargiya P, Camilleri M, Chedid V, Mandawat A, Erwin PJ, et al. (2019) Effects of promotility agents on gastric emptying and symptoms: A Systematic Review and Meta-analysis. Gastroenterology 156(6): 16501660.

15. Frieling T (2020) Clinically relevant effect of G-POEM or GES on gastric emptying-many open questions. Z Gastroenterol 58(9): 895-896.

16. Frieling $T$ (2021) Gastroparesis-too complicated for a simplistic therapeutical approach. Endoscopy 53(1): 98.

17. Shen S, Luo H, Vachaparambil C (2020) Gastric peroral endoscopic pyloromyotomy versus gastric electrical stimulation in the treatment of refractory gastroparesis: A propensity score-matched analysis of long term outcomes. Endoscopy 52(5): 349-358.

18. Ducrotte P, Coffin B, Bonaz B, Fontaine S, Bruley Des Varannes S (2020) Gastric electrical stimulation reduces refractory vomiting in a randomized crossover trial. Gastroenterology 158(3): 506-514.

19. Chu H, Lin Z, Zhong L, McCallum RW, HouX (2012) Treatment of highfrequency gastric electrical stimulation for gastroparesis. J Gastroenterol Hepatol 27(6): 1017-1026.

20. Lal N, Livemore S, Dunne D, Khan I (2015) Gastric electrical stimulation with the Enterra system: A systematic review. Gastroenterol Res Pract, p. 762972 .

21. Levinthal DJ, Bielefeldt K (2017) Systematic review and meta-analysis: Gastric electrical stimulation for gastroparesis. Auton Neurosci 202: 4555.

22. Zoll B, Jehangir A, Malik Z, Edwards MA, Petrov RV, et al. (2019) Gastric electric stimulation for refractory gastroparesis. J Clin Outcomes Manag 26(1): 27-38.

23. Frieling T, Wenzel G, Heise J, Kuhlbusch R (2005) Endoscopic anti-reflux procedures: what causes the clinical benefit? Gastroenterology 129(1): 397-398.

24. Arts J, Van Olmen A, D’Haens G, Sifrim D, Lerut A, et al. (2003) Radiofrequency delivery at the gastroesophageal junction in GERD improves acid exposure and symptoms and decreases esophageal sensitivity to acid. Gastroenterology 124: A148. 
25. Wenzel G, Kuhlbusch R, Heise J, Frieling T (2005) Relief of reflux symptoms after endoscopic gastroplication may be associated with reduced esophageal acid sensitivity: A pilot study. Endoscopy 37(3): 236-239.
26. Parkman HP (2020) Which endosurgical treatment for gastroparesis: Pyloromyotomy or gastric electrical stimulation?. Endoscopy 52(5): 330-331.

For possible submissions Click below: 